\title{
Caracterización del patrón proteico y perfil antigénico de larvas L3 de anisákidos de importancia médica aisladas de peces comerciales de la costa peruana \\ Characterization of the protein pattern and antigen profile of $\mathrm{L} 3$ larvae of medical importance in anisakids isolated from commercial fish of the peruvian coast
}

\author{
Rosa Martínez-Rojas ${ }^{1, a}$, Aarón Mondragón-Martínez ${ }^{1, b}$, Eduardo A. Pulido-Murillo ${ }^{2, c}$, Manuel Tantaleán-Vidaurre ${ }^{1, d}$ \\ ${ }^{1}$ Laboratorio de Parasitología de Fauna Silvestre y Zoonosis, Facultad de Ciencias Biológicas, Universidad Nacional Mayor de San Marcos. Lima, Perú. \\ ${ }^{2}$ Departamento de Parasitologia, Instituto de Ciências Biológicas, Universidade Federal de Minas Gerais. Belo Horizonte, Brasil. \\ ${ }^{a}$ Bióloga, magister en zoologia con mención en morfología y fisiologia. ORCID: https://orcid.org/0000-0002-5100-0452

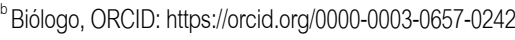 \\ 'Biólogo, magister en parasitologia, ORCID: https://orcid.org/0000-0002-9039-3068 \\ ${ }^{\mathrm{d}}$ Biólogo, doctor en ciencias biológicas
}

An Fac med. 2020;81(3):324-9. / DOI: https://doi.org/10.15381/anales.v81i3.17256

Correspondencia:

Rosa Martínez Rojas

rmartinezr@unmsm.edu.pe

Recibido: 8 de noviembre 2020

Aprobado: 18 de diciembre 2020

Publicación en línea: 30 de diciembre 2020

Conflictos de interés: Los autores declaran no tener conflictos de interés.

Fuente de financiamiento:

Vicerectorado de Investigación, Universidad Nacional Mayor de San Marcos código: B20102121.

Contribuciones de autoría: RMR: diseño del trabajo, obtención de resultados, análisis de los datos y redacción del manuscrito. AMM: recolección y aporte del material de estudio, análisis e interpretación de los datos. EPM: aporte del material de estudio e interpretación de los datos. MTV: revisión crítica del manuscrito y aprobación de la versión final.

Citar como: Martínez-Rojas R, Mondragón-Martínez A, PulidoMurillo E, Tantaleán-Vidaurre M. Caracterización del patrón proteico y perfil antigénico de larvas $L 3$ de anisákidos de importancia médica aisladas de peces comerciales de la costa peruana. An Fac med. 2020;81(3):324-9. DOI: https://doi. org/10.15381/anales.v81i3.17256

\section{Resumen}

Introducción. La anisakidosis es una zoonosis causada por la ingestión accidental de larvas $\left(\mathrm{L}_{3}\right)$ de anisákidos. Objetivo. Caracterizar el patrón proteico y perfil antigénico de la $\mathrm{L}$ de Anisakis simplex s.l. (tipo I), A. physeteris s.I. (tipo II) y Contracaecum osculatum s.I. aisladas de peces comerciales. Métodos. Se realizó una corrida electroforética en SDS-PAGE de los antígenos somáticos. Se inmunizó conejos experimentalmente y se evaluó por EITB. Resultados. El patrón proteico de Anisakis tipo I mostró 12 bandas, 18 Anisakis tipo II y C. osculatum 13, con las bandas 10 y $35 \mathrm{kDa}$ especificas para Anisakis tipo II, 28 y 77 para C. osculatum no presentes en Anisakis tipo I. Conclusión. se determinó bandas inmunogénicas específicas para Anisakis tipo I con las proteinas de peso molecular 11, 14, 25 y $40 \mathrm{kDa}$, para el tipo II de 9, 10, 12, 35 y 41 kDa, y C. osculatum 13, 15, 17, 30 y 47 kDa.

Palabras clave: Anisakis; Antígeno; Immunoelectroforesis; Western Blotting; Perú (fuente: DeCS BIREME).

\section{Abstract}

Introduction. Anisakidosis is a zoonosis caused by accidental ingestion of anisakid larvae $\left(L_{2}\right)$. Objective. To characterize the protein pattern and antigenic profile of the $L$ of Anisakis simplex s.l. (type I), $A$. physeteris s.I. (type II) and Contracaecum osculatum s.I. commercial fish isolated. Methods. An SDS-PAGE electrophoretic run of the somatic antigens was performed. Rabbits were immunized experimentally and evaluated by EITB. Results. The protein pattern of Anisakis type I showed 12 bands, 18 Anisakis type II and C. osculatum 13, with bands 10 and $35 \mathrm{kDa}$ specific for Anisakis type II, 28 and 77 for C. osculatum, not present in Anisakis type I. Conclusion. Specific immunogenic bands were determined for Anisakis type I with the molecular weight proteins $11,14,25$ and $40 \mathrm{kDa}$, for type || of 9, 10,12, 35 and $41 \mathrm{kDa}$ and $C$. osculatum 13, 15, 17, 30 and $47 \mathrm{kDa}$.

Keywords: Anisakis; Antigen; Immunoelectrophoresis; Western Blotting; Peru (source: MeSH NLM). 


\section{INTRODUCCIÓN}

La anisakidosis es una zoonosis parasitaria causada por la ingestión accidental de larvas del estadio $L_{3}$ de nematodos Anisakidae, Anisakis simplex s.l. (tipo I), A. physeteris s.l. (tipo II), Pseudoterranova decipiens s.l. (Phocanema d.), Contracaecum osculatum s.l. e Hysterothylacium sp. (1). Las larvas se encuentran enquistadas sobre la superficie visceral o tejido muscular de peces marinos que son los hospederos intermediarios y/o paraténicos. El hombre es un hospedero accidental, se infecta con la larva $L_{3}$ al ingerir pescado marinado insuficientemente cocido ${ }^{(2)}$. Los hospederos definitivos de las formas adultas de Anisakis sp., son mamíferos marinos, principalmente cetáceos ${ }^{(2)}$. En Perú, se ha descrito Anisakis sp. en los delfines, lobo marino y el cachalote; C. osculatum en el lobo fino y Contracaecum spp. en aves marinas ${ }^{(3)}$.

Desde que se publicó el primer caso humano de lesión gastrointestinal causada por Anisakis, actualmente, se han reportado más de 20000 casos de anisakiasis en todo el mundo ${ }^{(5,6)}$, la mayoría reportados en Japón (2). España es el segundo país que reporta más casos de anisakiasis a nivel global, estimándose entre 7700 a 8320 casos anuales debido a la costumbre del consumo de anchoas marinadas $^{(4)}$. Se ha sugerido que la anisakiasis es una zoonosis parasitaria emergente, debido a un incremento de casos en las dos últimas décadas ${ }^{(4,6,7)}$.

Las larvas $L_{3}$ de Anisakis, principalmente A. simplex s.l., al ingresar al estómago o intestino, origina lesiones granulomatosas o abscesos que se caracterizan por necrosis y hemorragia con infiltración eosinofílica masiva, fiebre y diarrea ${ }^{(1)}$. También producen una reacción alérgica inducida por ciertos antígenos del parásito, que se presenta en algunas personas luego de la ingesta de pescado o cefalópodos, caracterizada por cuadros de urticaria, angioedema o respuesta anafiláctica, al que se le ha denominado anisakidosis gastroalérgica (2).

En el Perú, no se considera un problema de salud pública porque se desconoce la prevalencia real de la infección, a pesar que las larvas de Anisakis se han reportado en más de 20 especies de peces marinos y en Dosidicus gigas "calamar gigante" (8); $\sin$ embargo, se han reportado casos humanos comprobados de anisakidosis ${ }^{(9)}$, uno por endoscopía por larva de Anisakis sp. adherida a la mucosa gástrica y dos casos de personas que eliminaron la larva de $P$. decipiens por vía oral ${ }^{(10)}$. Durante el fenómeno El Niño 1997-1998 se describieron probables casos de anisakidosis; posteriormente, se reportó otro caso de infección por P. decipiens ${ }^{(3)}$ y un probable brote en 5 miembros de una familia en Lima, que presentaron síntomas compatibles con anisakiasis aguda gástrica después de consumir cebiche de "perico" Coryphaena hippurus ${ }^{(11)}$.

El hombre no es el hospedero final natural de Anisakis; por lo tanto, estas larvas pueden ser expulsadas o penetrar en la mucosa gástrica donde muere y se descompone en los tejidos ${ }^{(1)}$. En este último caso es importante el antígeno somático porque distingue entre 30 a 40 bandas ${ }^{(2)}$. Asimismo, en infección experimental en ratones, los niveles de anticuerpos principalmente IgM e IgG contra antígenos somáticos pueden permanecer hasta 42 días después de la infección e inclusive mantenerse en niveles altos por un largo período (2).

Existe escasa información referente al patrón proteico de larvas de Anisakis tipo
I, tipo II y C. osculatum; sin embargo, hay reportes sobre el perfil antigénico de la larva de Anisakis tipo I, particularmente con la Ag de excreción-secreción (E/S) utilizado para evaluar la seroprevalencia (12), pero no de Anisakis tipo II y C. osculatum.

Identificar, caracterizar y determinar las proteínas antigénicas de los anisákidos es de utilidad para la búsqueda de anticuerpos en pacientes con problemas gástricos, después de la ingesta de pescado o de etiología desconocida, ya que brinda una potencial herramienta específica importante para el diagnóstico de la anisakiasis.

Por ello, el objetivo de nuestro estudio fue caracterizar el patrón proteico y perfil antigénico de las larvas de Anisakis tipo I, Anisakis tipo II y C. osculatum de importancia médica aisladas de peces comerciales de la costa peruana.

\section{MÉTODOS}

Obtención de la larva infectante (L3) Se aislaron 146 larvas de Anisakis tipo I (figura 1) del peritoneo visceral de 30 especímenes de Trachurus picturatus mur-

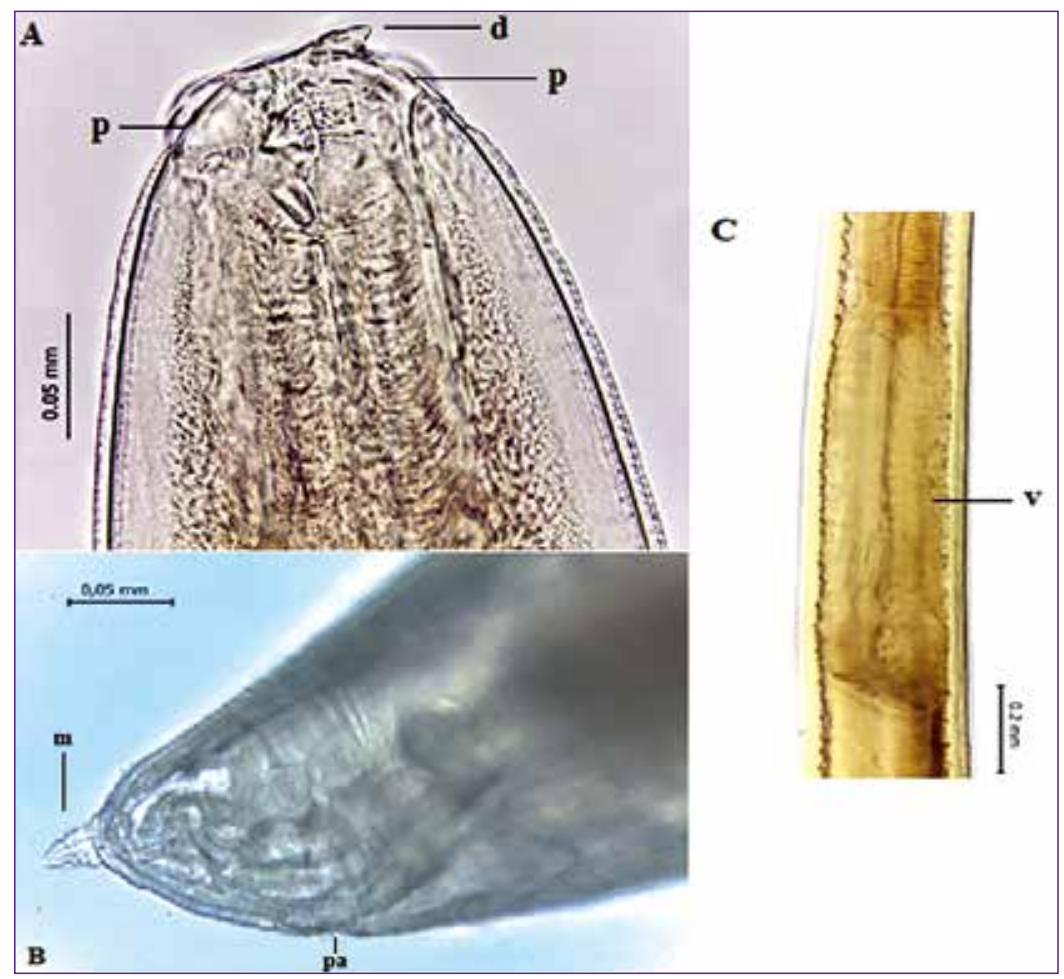

Figura 1. Microfotografias de Anisakis sp. tipo I. A. Región anterior, mostrando el diente (d) y papilas (p); B. Región posterior, con el poro anal (pa) y mucrón (m); C. Parte ventrícular (v). 
phyi "jurel", 75 larvas de Anisakis tipo II (figura 2) de 50 ejemplares de Scomber japonicus peruanus "caballa" y 85 larvas de C. osculatum (figura 3) de 50 Mugil cephalus "lisas", provenientes del terminal pesquero de Ventanilla, Callao $\left(11^{\circ}\right.$ 59' 20" S y $77^{\circ} 07^{\prime} 34^{\prime \prime}$ O), y del Puerto de San Andrés en Pisco, Ica (13 43' 59" S y $76^{\circ} 13^{\prime} 30^{\prime \prime}$ O), durante los años 2001 y 2002. Las larvas fueron identificadas morfológicamente ${ }^{(13)}$ antes de ser conservadas a $-20 \cong \mathrm{C}$ hasta su procesamiento. El estudio se llevó a cabo en el Laboratorio de Parasitología de la Facultad de Ciencias Biológicas e Inmunología y Bioquímica del Instituto de Medicina Tropical de la Universidad Nacional Mayor de San Marcos.

\section{Caracterización del patrón proteico por SDS-PAGE}

a. Obtención de antígeno. Se prepararon antígenos somáticos (AS) de 30 larvas de Anisakis tipo I, tipo II y C. osculatum. Se homogeneizó en frío utilizando buffer fosfato salino estéril (PBS pH 7,2). Se sonicaron a $4^{\circ} \mathrm{C}$ utilizando un desintegrador ultrasónico (Braun Sonic 2000) y se centrifugó a 8000 rpm x 30 min (centrífuga refrigerada Sorval). Al sobrenadante se le agregó $2 \mathrm{mM}$ de fluoruro de fenilmetilsulfonilo (PMSF) solución inhibidora de la proteasa (1:10 en PBS a pH 7,2). La cantidad de proteínas se determinó por el método de Bradford ${ }^{(14)}$, leyendo la absorbancia a $595 \mathrm{~nm}$.

b. Separación de las proteínas por electroforesis en SDS-PAGE. Para el análisis de las proteínas, se realizaron corridas electroforéticas en geles de poliacrilamida dodecil sulfato de sodio (SDS-PAGE) al $15 \%$, según la metodología descrita por Laemmli ${ }^{(15)}$. Se usó 20 ug de proteína por carril, con buffer de muestra en condición reductora y no reductora. Con un patrón de peso molecular de 14 - 94 kDa (Sigma-Aldrich-Química). Se corrió a $25 \mathrm{~mA} / 5 \mathrm{~h}$ a $4{ }^{\circ} \mathrm{C}$.

c. Coloración de las proteínas totales. Los geles se colocaron en una solución fijadora (ácido acético al 10\% y metanol al $50 \%$ ) y teñidos por inmersión en 0,125\% de azul de Comassie en metanol, ácido acético y agua (50:10:45) durante toda
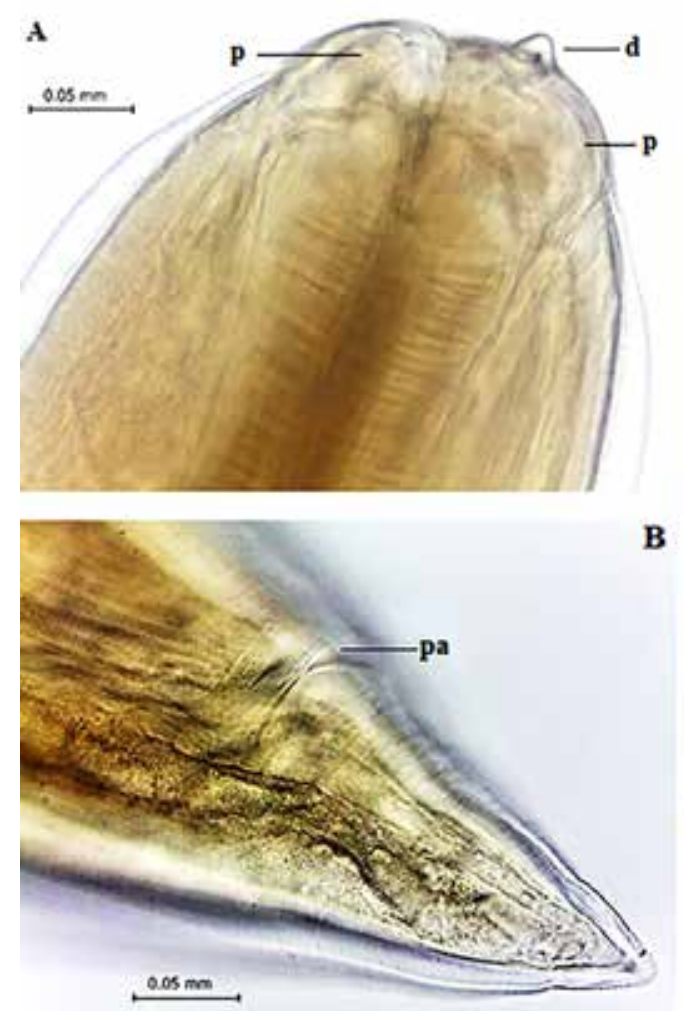

Figura 2. Microfotografias de Anisakis sp. tipo II. A. Región anterior, diente (d) y papilas (p); B. Región posterior, poro anal (pa); C. Parte ventricular (v). la noche y desteñidos en metanol, ácido acético y agua (20:14:76).

\section{Caracterización del perfil antigénico por Western blot (EITB)}

a. Obtención de suero hiperinmune. Se inmunizaron seis conejos (New Zealand) de 1,5-2 meses de edad entre 2,5 a $3 \mathrm{Kg}$ de peso con los extractos somáticos (AS) de las larvas de acuerdo al método propuesto en la Guide for the care and use of Laboratory Animals de la Oficina de Bienestar para Animales de Laboratorio (16). Se le aplicó una concentración de $1 \mathrm{mg} /$ $\mathrm{mL}$ de antígeno distribuido en 4 dosis en una proporción 1:1 con el adyuvante de Freund completo (Sigma) en la primera dosis y el incompleto en las tres últimas dosis. Se inmunizó por vía subcutánea con intervalos de 15 días. Previo a la primera inmunización se obtuvo una muestra de sangre (suero control negativo) y después de cada inmunización. Se evaluó el título de anticuerpos (IgG) específicos mediante ELISA indirecto (ensayo por inmunoabsorción ligado a enzimas) ${ }^{(17)}$.

\section{b. Análisis del antígeno somático (SDS- PAGE)}

Para el análisis antigénico, se fraccionaron los Ag por electroforesis en gel SDS-PAGE usando Mini protean II (BioRad) ${ }^{(18)}$. Se corrió en un gel de gradiente de $5-22,5 \%$ y el stacking acrilamida al $3 \%$. Se diluyó $2 \mu \mathrm{g} / \mathrm{mL}$ de $\mathrm{Ag}$ con un buffer de muestra en dilución $1: 1$, preparado con $0,5 \mathrm{M}$ Tris- $\mathrm{HCl}(\mathrm{pH} 6,8)$, conteniendo SDS al 2\%, azul de bromofenol 0,1\%, 2- mercaptoethanol $2 \%$ y glicerol $20 \%$. Se aplicó el $\mathrm{Ag}$ a una concentración de $1 \mu \mathrm{L} / \mathrm{mm}$, iniciando la corrida electroforética a $50 \mathrm{~V}$ y 0,6 A/5 min, incrementando a $100 \mathrm{~V} / 50$ min. Se usó un buffer de corrida a pH 8,6 (Tris- $\mathrm{HCl} /$ ácido bórico en $0,1 \%$ de SDS). Se incluyó un estándar de peso molecular de amplio rango (7,2-208 kDa, Bio-Rad).

c. Evaluación de proteínas inmunogénicas por Western blot

Las fracciones antigénicas fueron transferidas sobre un papel de nitrocelulosa con poro de $0,45 \mu \mathrm{m}$ y en un buffer Tris- $\mathrm{HCl}$ a $\mathrm{pH} 9,18$ y 40\% (v/v) de metanol, utilizando un mini trans-blot para transferencia electroforética (Bio-Rad), aplicándose $100 \mathrm{~V}$ y 2,0 A por $2 \mathrm{~h}{ }^{(18)}$. Luego, 


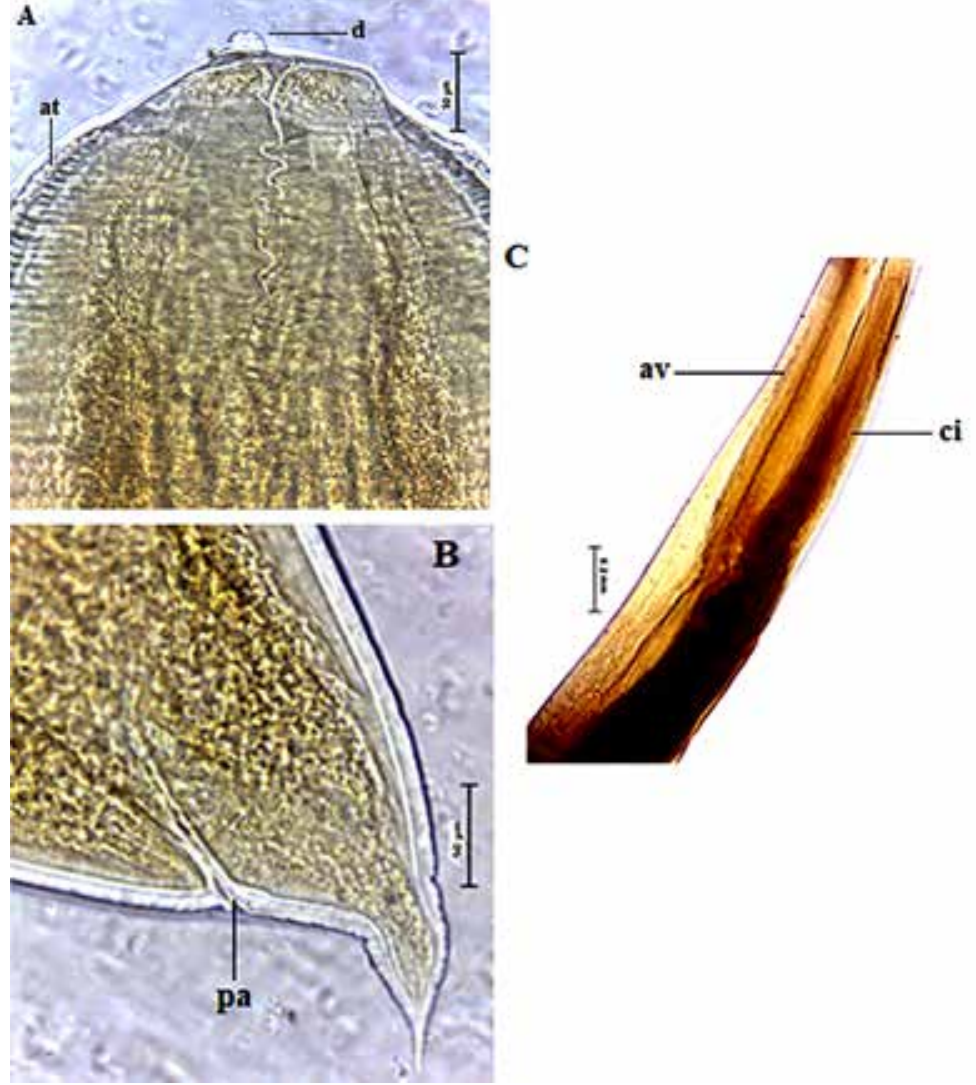

Figura 3. Microfotografias de Contracaecum osculatum. A. Región anterior, diente (d), anulaciones transversales (at) de la cutícula; B. Región posterior, poro anal (pa); C. ciego intestinal (ci) y apéndice ventricular (av).

se enfrentaron a los antisueros de conejo (Anisakis tipo I, II y C. osculatum) en una dilución 1/50 en PBS-Tween 20 al 0,3\% (buffer de lavado) y leche descremada al $5 \%$, se incubó en agitación a Ta/1 h y se dejó a 4 ํ. $\mathrm{C}$ toda la noche. Posteriormente, se lavó tres veces, usando el buffer a $56^{\circ} \mathrm{C}$ en el primer lavado. Se agregó antiinmunoglobulina $\mathrm{G}$ de conejo marcado con peroxidasa (Bio-Rad) diluido 1/1000 con PBS-Tween 20 al 0,3\% e incubándose en agitación a Ta/1h. Finalmente, se lavó con el buffer 3 veces y se agregó el buffer de revelado (10 mL PBS, $5 \mathrm{mg}$ de 3-3' Diaminobencidina, $30 \% \mathrm{H}_{2} \mathrm{O}_{2}$ ). Las reacciones positivas aparecieron a los minutos. Se detuvo la reacción lavando con agua destilada.

\section{RESULTADOS}

Se caracterizó el perfil proteico de los extractos somáticos de las larvas de Ani- massie en condiciones reductoras: para Anisakis tipo I, 12 bandas proteicas de 11 a $52 \mathrm{kDa}(11,14,17,18,21,25,30,38$, 40, 42, 47, 52); Anisakis tipo II, 18 bandas de 10 a $73 \mathrm{kDa}(10,11,14,15,17,18,21$, $25,30,35,38,40,42,47,52,58,64,73$ $\mathrm{kDa})$, y C. osculatum, 13 bandas de 11 a $77 \mathrm{kDa}(11,14,15,17,24,28,30,40,42$, $47,51,73,77 \mathrm{kDa})$. Figura 4.

Asimismo, se hallaron proteínas similares para las tres especies con peso molecular de 11, 14, 17, 30, 40, 42 y $47 \mathrm{kDa}$. Anisakis tipo I y II comparten casi todas las proteínas, excepto el tipo II que presenta además las bandas de 10, 15, 35, 58,64 y $73 \mathrm{kDa}$.

Se evaluaron los Ag por la prueba de ELISA, frente a los sueros hiperinmunes de conejo, utilizando diferentes concentraciones: $1 / 250,1 / 500,1 / 1000,1 / 2000$ y $1 / 4000$, obteniendo una buena respuesta antigénica hasta la dilución 1/2000, disminuyendo en la última dilución.

Se determinó el perfil antigénico de Anisakis tipo I, II y C. osculatum, frente a los sueros hiperinmunes de conejo, por Western blot. Para Anisakis tipo I, 06 bandas antigénicas, con pesos moleculares de $11,14,18,21,25$ y $40 \mathrm{kDa} ; 07$ para el tipo II de 9, 10, 12, 24, 30, 35 y $41 \mathrm{kDa}$ (figura 5) y 07 para C. osculatum de 11 , $13,15,17,24,30$ y $47 \mathrm{kDa}$ (figura 6). GE, visualizándose mejor con azul de Co-

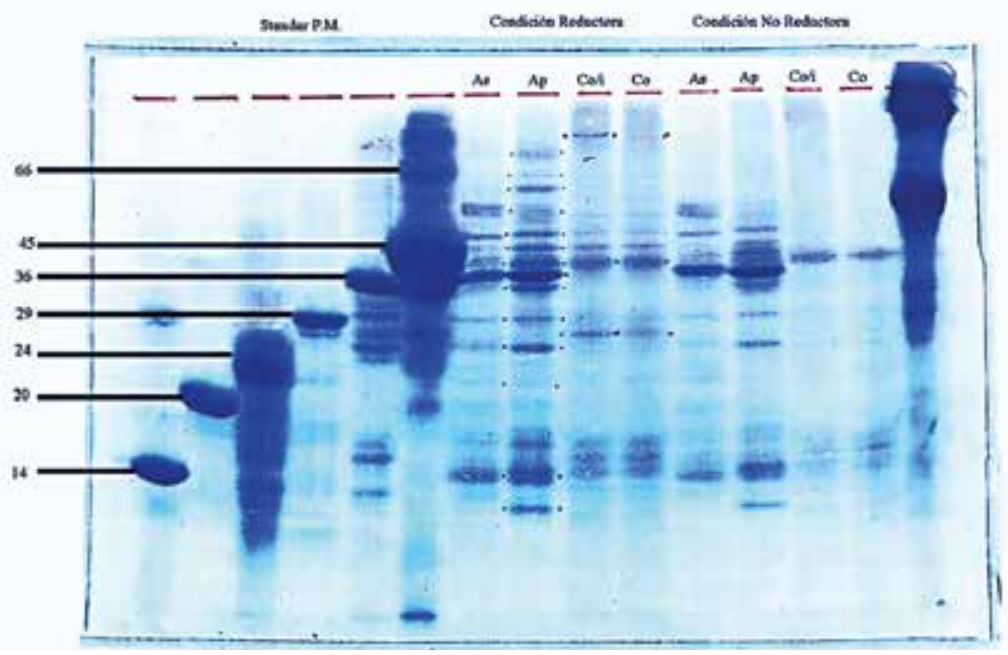

Figura 4. Patrón proteico de los extractos somáticos de las larvas L3 de Anisakis tipo I (As), tipo II (Ap) y Contracaecum osculatum (Co) sin inhibidor y con inhibidor (Co/i), en condición reductora y no reductora por SDS- PAGE. Standar P.M. (Estándar de Peso molecular) de 14, 20, 24, 29, 36, 45, 66 y 94 kDa (Sigma). 


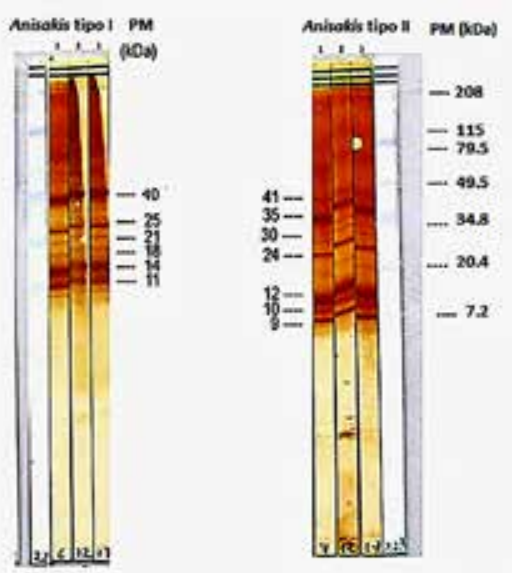

Figura 5. Perfil antigénico de las larvas $\mathrm{L} 3$ de Anisakis tipo I y II en las concentraciones: 1,5 (1), 2,0 (2) y 2,5 (3) $\mu \mathrm{g}$, mediante Western blot. En Anisakis tipo I se obtuvieron 6 bandas proteicas inmunogénicas $(11,14,18,21,25$, $40 \mathrm{kDa}$ ) y en A. tipo II 7 bandas $(9,10,12,24$, 30, 35, $41 \mathrm{kDa}$ ). PM: peso $\mathrm{m}$.

\section{DISCUSIÓN}

El análisis de las proteínas de los extractos somáticos se encontró que Anisakis tipo I comparte las bandas proteicas de $11,14,17,30,40,42$ y 47 kDa con el tipo II y C. osculatum, diferenciándose Anisakis tipo II por las bandas de 10 y 35 kDa y C. osculatum de 28 y 77 kDa.

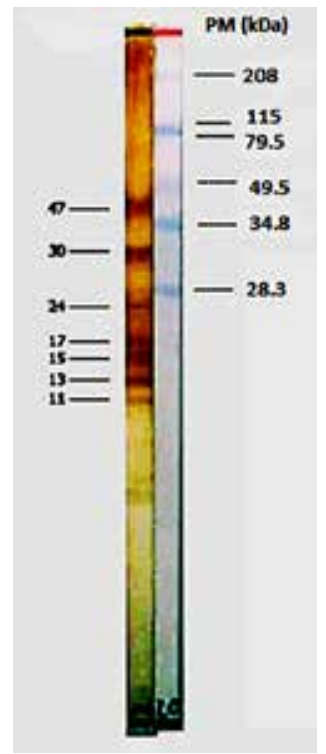

Figura 6. Perfil antigénico de la larva $L_{3}$ de $C$. osculatum en una concentración de 2,5 $\mathrm{\mu g}$, mediante Western blot. Se obtuvieron bandas inmunogénicas de 11, 13, 15, 17, 24, 30, 47 kDa. PM: peso molecular.
Asimismo, Anisakis tipo I y II comparten tres bandas proteicas de 18, 21 y $38 \mathrm{kDa}$ y el tipo II y C. osculatum una de $73 \mathrm{kDa}$ indicando un parentesco entre las especies. Actualmente utilizando marcadores genéticos moleculares sólo del género de Anisakis se reconocen 9 especies y en el complejo Anisakis simplex se incluyen a 3 especies hermanas: $A$. simplex "senso estricto", A. pegreffii y A. berlandi (4).

Algunos autores mencionan, haber distinguido entre 30 a 40 bandas en el extracto somático de $A$. simplex s.l., con pesos moleculares entre 13 a 150 kDa, los cuales fueron reconocidos por anticuerpos en el suero de ratones experimentalmente infectados con las larvas ${ }^{(2)}$. Así también, se ha reportado que la proteína de $14 \mathrm{kDa}$, está presente en Ascaris lumbricoides, $A$. suum y Toxocara canis, utilizando los AS o $\mathrm{E} / \mathrm{S}{ }^{(2)}$; e inclusive con la Ag pseudocelómico de A. suum; por lo tanto, la banda de 14 kDa es una proteína característica en los anisákidos estudiados y los ascáridos antes mencionados ${ }^{(19)}$.

En cuanto al perfil antigénico, en este estudio se ha caracterizado para Anisakis tipo I: 06 bandas de 11, 14, 18, 21, 25 y 40 kDa; para el tipo II: 07 de 9, 10, 12, 24, 30, 35 y 41 kDa; y C. osculatum 07 de 11, $13,15,17,24,30$ y $47 \mathrm{kDa}$. Se ha reportado dos enzimas de 23,4 y 46,1 kDa en el antígeno de $\mathrm{E} / \mathrm{S}$ de $A$. simplex (tipo I), con valor antigénico ${ }^{(2)}$. Nosotros identificamos bandas antigénicas tanto en Anisakis tipo I (25 kDa) como en el tipo II (24 kDa) y C. osculatum (24 kDa), muy similares a las reportadas (2); la segunda (46.1 kDa) es una banda muy marcada en el patrón proteico de las tres especies. Igualmente determinaron una proteína de 25 kDa en el E/S de A. simplex s.l. de importancia antigénica, esta proteína denominada Ani s 1 se describe como potente alérgeno, importante en el serodiagnóstico ${ }^{(2)}$.

Anisakis tipo I presentó una banda de 40 kDa y el tipo II de 41 kDa frente al antisuero de conejo, no presente en $C$. osculatum, pero si en el patrón proteico (42 $\mathrm{kDa}$ ); otros autores determinaron bandas semejantes de 40 y 42 kDa correspondientes al anticuerpo monoclonal Ani s 3 (41 kDa), que se hace más intensa en el purificado mediante Western blot ${ }^{(2)}$. Asimismo, señalan que la banda de $40 \mathrm{kDa}$ de $A$. simplex s.l. corresponde a la enzima hialuronidasa, que tiene la propiedad de degradar glicosaminoglicano de sulfato de condroitina, enzima que produce hidrólisis del tejido permitiendo a la larva invadir la mucosa ${ }^{(2)}$, marcador importante en el serodiagnóstico de anisakiasis.

Con relación a las bandas antigénicas de bajo peso molecular, en $A$. simplex s.I. se ha reportado las bandas $11-18 \mathrm{kDa}{ }^{(2)}$, reconocida en el suero de ratones infectados experimentalmente, pero no especifican las bandas intermedias que observamos en las tres especies, en Anisakis tipo I (11, 14 y 18 kDa), tipo II (9, 10 y 12 kDa) y en $C$. osculatum $(11,13,15$ y $17 \mathrm{kDa})$; asimismo, se menciona que la banda 17 kDa en $A$. simplex s.l. es responsable de una reacción alérgica ${ }^{(20)}$, en nuestro estudio también está presente en el perfil antigénico de $C$. osculatum, pero en el patrón proteico se encuentra en Anisakis tipo I y II.

Las larvas recolectadas durante los años de muestreo permitieron estandarizar la técnica sin constituir ninguna limitación en el presente estudio.

En conclusión, se determinaron bandas inmunogénicas específicas, para Anisakis tipo I las proteínas de 11, 14, 25 y 40 kDa, tipo II de 9, 10, 12, 35 y 41 kDa y C. osculatum de 13, 15, 17, 30 y 47 kDa, las que podrían ser consideradas importantes marcadores de serodiagnóstico.

\section{AGRADECIMIENTOS}

Al Dr. Herman Vildózola, ex- Director del Instituto de Medicina Tropical de la Universidad Nacional Mayor de San Marcos y a la bióloga Elizabeth Dávila T. (QEPD).

\section{REFERENCIAS BIBLIOGRÁFICAS}

1. Ishikura H, Kikuchi K, Nagasawa K, Ooiwa T, Takamiya H, Sato N, Sugane K. Anisakidae and anisakidosis. Prog Clin Parasitol. 1992;3:43-102.

2. Audicana MT, Kennedy MW. Anisakis simplex: from obscure infectious worm to inducer of immune hypersensitivity. Clin Microbiol Rev. 2008 Apr;21(2):360-79. DOI: 10.1128/CMR.00012-07

3. Cabrera R, Trillo-Altamirano M. Anisakidosis: ¿Una zoonosis parasitaria marina desconocida o emergente en el Perú? Rev Gastroenterol Perú. 2004;24:335-342. 
4. Bao M, Pierce GJ, Pascual S, González-Muñoz M, Mattiucci S, Mladineo I, et al. Assessing the risk of an emerging zoonosis of worldwide concern: anisakiasis. Sci Rep. 2017;13;7:43699. DOI: 10.1038/ srep43699.6

5. Hochberg NS, Hamer DH. Anisakidosis: Perils of the deep. Clin Infect Dis. 2010; 51(7):806-12. DOI: $10.1086 / 656238$

6. Jofré ML, Neira OP, Noemí HI, Cerva CJ. Pseudoterranovosis y sushi. Rev Chil Infect. 2008;25(3):200206

7. González Quijada S, González Escudero R, Arias García L, Gil Martína AR, Vicente Serrano J, Corral Fernández E. Manifestaciones digestivas de la anisakiasis: descripción de 42 casos. Rev Clin Esp. 2005;205(7):311-315

8. Luque JL, Cruces C, Chero J, Paschoal F, Alves PA. Checklist of Metazoan parasites of fishes from Peru. Neotrop Helminthol. 2016;10(2):301-375.

9. Barriga J, Salazar F, Barriga E. Anisakiasis: Presentación de un caso y revisión de la literatura. Rev Gastroent Perú. 1999;19:317-323.
10. Tantaleán V, Huiza A. Nematode larvae with medica importance found in sea fish of Peruvian shore, with two records of human infections. Rev Per Med Trop. UNMSM.1993; 7:61-65

11. Cabrera R. Anisakiasis outbreak by Anisakis simplex larvae associated to Peruvian food in Spain. Rev Esp Enferm Dig. 2010;102(10):610-611. DOI: 10.4321/ s1130-01082010001000011

12. Gómez-Mateos M, Valero-López A, Rubia-Nieto T. Reconocimiento de los antígenos excretores/ secretores de Anisakis tipo I y evolución de la IgE en ratas infectadas experimentalmente. Enferm Infecc Microbiol Clin. 2014;32(8):491-496. DOI: 10.1016/j. eimc.2013.09.009

13. Koyama T, Kobayashi A, Kumada M, Komiya Y, Oshima T, Kagei N, et al. Morphological and Taxonomical studies on Anisakidae larvae found in marine fishes and squids. Fisheries and Marine Service. Biological Station. St.Jhon's Nfld. Translation series No 3082. Japan J Parasitology.1974;18(5): 466-487.

14. Bradford MH. Rapid and sensitive method for the quantitation of microgram quantities of protein utilizing the principle of protein dye binding. Anal Biochem. 1976;72: 248-254.
15. Laemmli U. Cleavage of structure proteins during the assembly of the head of bacteriophage T4. Nature. 1970;227:680-685.

16. Guide Laboratory Animals for The Care and Use of Institute for Laboratory Animal Research Division on Earth and Life Studies. National Research Council 2011;220pp.

17. Tijssen P. Practice and theory of enzyme inmunoassays. Laboratory techniques in biochemestry and molecular biology. Elsevier Science Publishers B. V. (Biomedical Division). 1985; 529 pp.

18. Tsang V, Boyer A, Chou-Pong P. Enzyme-linked Inmunoelectrotransfer blot technique (Western blot) for human inmunodeficiency virus type 1 (HIV-1) ntibodies. Dept. Health and Human Services.CDC, Atlanta. Inmunology series No 15. 1991; 41 pp.

19. Frontera E, Serrano F, Carrón A, Mora J, Pérez J, Reina D. Caracterización antigénica de Ascaris suum mediante SDS-PAGE y Western blotting. Invest Agr Prod Sanid Anims. 2001;16(1):153-163.

20. Daschner A, Alonso-Gómez A, Mora C, MorenoAncillo A, Villanueva R, López-Serrano MC. Anisakiasis gastro-alérgica con parasitación masiva. Rev Esp Alergol Inmunol Clin. 1997;12(6):370-372. 